\title{
BMJ Open Burden of chronic diseases associated with periodontal diseases: a retrospective cohort study using UK primary care data
}

\author{
Dawit T Zemedikun (D) , ${ }^{1}$ Joht Singh Chandan (D) , ${ }^{1}$ Devan Raindi, ${ }^{2}$ \\ Amarkumar Dhirajlal Rajgor, ${ }^{3,4}$ Krishna Margadhmane Gokhale, ${ }^{1}$ Tom Thomas, ${ }^{5}$ \\ Marie Falahee (10 , ${ }^{6}$ Paola De Pablo, ${ }^{6}$ Janet M Lord (i) , ${ }^{6}$ Karim Raza, ${ }^{6,7,8}$ \\ Krishnarajah Nirantharakumar ${ }^{1}$
}

To cite: Zemedikun DT, Chandan JS, Raindi D, et al. Burden of chronic diseases associated with periodontal diseases: a retrospective cohort study using UK primary care data. BMJ Open 2021;11:e048296. doi:10.1136/ bmjopen-2020-048296

- Prepublication history and additional supplemental material for this paper are available online. To view these files, please visit the journal online (http://dx.doi.org/10.1136/ bmjopen-2020-048296).

DTZ and JSC are joint first authors.

$\mathrm{KR}$ and $\mathrm{KN}$ are joint senior authors.

Received 22 December 2020 Accepted 19 November 2021

Check for updates

(c) Author(s) (or their employer(s)) 2021. Re-use permitted under CC BY-NC. No commercial re-use. See rights and permissions. Published by BMJ.

For numbered affiliations see end of article.

Correspondence to Dr Joht Singh Chandan; j.s.chandan.1@bham.ac.uk

\section{ABSTRACT}

Objectives To identify the association between periodontal diseases (gingivitis and periodontitis) and chronic diseases including cardiovascular disease, cardiometabolic disease, autoimmune disease and mental ill health.

Design Retrospective cohort.

Setting IQVIA Medical Research Data-UK between 1 January 1995 and 1 January 2019.

Participants 64379 adult patients with a general practitioner recorded diagnosis of periodontal disease (exposed patients) were matched to 251 161 unexposed patients by age, sex, deprivation and registration date.

Main outcome measures Logistic regression models accounting for covariates of clinical importance were undertaken to estimate the adjusted $\mathrm{OR}(\mathrm{aOR})$ of having chronic diseases at baseline in the exposed compared with the unexposed group. Incidence rates for each outcome of interest were then provided followed by the calculation of adjusted HRs using cox regression modelling to describe the risk of outcome development in each group.

Results The average age at cohort entry was 45 years and the median follow-up was 3.4 years. At study entry, the exposed cohort had an increased likelihood of having a diagnosis of cardiovascular disease (aOR 1.43; 95\% Cl 1.38 to 1.48), cardiometabolic disease (aOR 1.16; 95\% Cl 1.13 to 1.19 ), autoimmune disease (aOR 1.33; $95 \% \mathrm{Cl} 1.28$ to 1.37) and mental ill health (aOR 1.79; $95 \% \mathrm{Cl} 1.75$ to 1.83 ) compared with the unexposed group. During the follow-up of individuals without pre-existing outcomes of interest, the exposed group had an increased risk of developing cardiovascular disease (HR 1.18; 95\% $\mathrm{Cl} 1.13$ to 1.23), cardiometabolic disease (HR 1.07; 95\% Cl 1.03 to 1.10), autoimmune disease (HR 1.33; $95 \% \mathrm{Cl} 1.26$ to 1.40 ) and mental ill health (HR 1.37; $95 \% \mathrm{Cl} 1.33$ to 1.42 ) compared with the unexposed group.

Conclusions In this cohort, periodontal diseases appeared to be associated with an increased risk of developing cardiovascular, cardiometabolic, autoimmune diseases and mental ill health. Periodontal diseases are very common; therefore, an increased risk of other chronic diseases represent a substantial public health burden.
Strengths and limitations of this study

- This is the largest epidemiological study exploring the health outcomes of periodontal disease using primary care records.

- This was the first study to explore and quantify the association between mental ill health and periodontal diseases.

- Periodontal coding was not validated prior to this study so there may be misclassification bias.

- Outcomes of interest were adjusted for known covariates recorded in primary care.

\section{INTRODUCTION}

Poor oral health is extremely common and is frequently characterised by chronic inflammation. ${ }^{1}$ Advanced stages manifest as periodontitis where there is irreversible damage to local bone and tissue. ${ }^{2}$ Earlier stages include gingivitis, a reversible inflammation of the gingiva initiated by dental plaque. ${ }^{2}$ This spectrum from gingivitis to periodontitis, is widely termed 'periodontal diseases. ${ }^{2}{ }^{3}$ Although, the exact aetiological mechanisms have yet to be fully elucidated, the development of a dysbiotic microbial biofilm, overactivation of inflammatory pathways and genetic susceptibility are all implicated. ${ }^{24-6}$

Progressive periodontal disease leads to a reduction in quality of life due to problems relating with mastication (due to tooth loss), aesthetics (due to gum recession) and verbal communication. ${ }^{278}$ Periodontal disease also results in a systemic proinflammatory state which in itself is implicated in the aetiology of chronic diseases including cardiovascular disease (CVD), cardiometabolic disease (CMD), mental ill health (MIH) and autoimmune disease (AID), each of which are highly prevalent and potentially preventable causes 
of global morbidity and mortality. ${ }^{1-17}$ Therefore, a high prevalence of periodontal disease could translate to a substantial burden of morbidity and associated mortality. Epidemiological data have demonstrated associations between periodontitis and all-cause mortality in Western European males (adjusted HR (aHR) 1.57; 95\% CI 1.04 to 2.36). ${ }^{18}$ Although, this relationship could be explained through activation of a proinflammatory state, there is a lack of robust epidemiological evidence as many of these chronic diseases share similar pathogenic pathways, often mediated by lifestyle factors including smoking and socioeconomic status. $^{219-22}$

The association between periodontal disease and CVD is one of the more commonly researched. In 2012, the American Heart Association highlighted that, despite the literature supporting an association between periodontitis and atherosclerotic disease independent of known confounders, due to methodological limitations of available observational studies they were not able to confirm a causal relationship. ${ }^{23}$ Existing studies are limited by an inability to distinguish reverse causality or account for recall bias (case-control or cross-sectional designs), absence of adequate confounder control, lack of generalisability to other populations and heterogeneity in definitions of exposure and outcomes. ${ }^{23-25}$ A 2019 joint workshop held between the European Federation of Periodontology (EFP) and World Heart Federation confirmed robust evidence for positive associations between periodontitis and CVD/cerebrovascular disease including an increased risk of first cardiac or cerebrovascular event in patients with severe periodontitis. ${ }^{26}$

A recent review from the US Center for Disease Control and Prevention assessed the relationships between periodontal disease and other chronic diseases suggested that after CVD, the next most frequent association with periodontal disease was with levels of type 2 diabetes mellitus (T2DM) control. Emerging randomised trials suggest that treatment of periodontal disease reduces haemoglobin A1c (HbA1c) levels in patients with diabetes. ${ }^{27-2928}$ However, there is limited evidence exploring the risk of T2DM subsequent to periodontal disease and further investigation is needed. ${ }^{30}$ Existing evidence suggests an association with AID such as rheumatoid arthritis (RA) and Sjogren's syndrome (SS), however, this is yet to be validated in longitudinal cohort datasets accounting for important covariates. ${ }^{31-33}$ Few studies have explored the association between periodontal disease and subsequent MIH though a bidirectional mechanism relating to inflammation, psychosocial effects and the impact of psychopharmacological therapies has been proposed. ${ }^{34} 35$

It is important to strengthen understanding of the link between oral health and chronic diseases as cost-effective dental interventions are available that could be preventive, reducing the subsequent public health burden of disease. ${ }^{2}$ Therefore, we have conducted the first retrospective cohort study using a large medical dataset to explore the association between poor oral health and a range of chronic diseases including CVD, CMD, MIH and AID.

\section{METHODS}

\section{Study design and data source}

This study is a population based, retrospective open cohort study using IQVIA Medical Research Data (IMRDUK), previously known as The Health Improvement Network (THIN) database. The study period was set between 1 January 1995 and 1 January 2019. An open cohort study allows patients to enter and exit the study at different time points, with each patient only contributing person years of follow-up from the time of cohort entry (index date) to the time they leave the cohort (exit date).

During this study period, the database consisted of pseudoanonymised electronic medical records of more than 15 million patients derived from 787 general practices using the Vision software system. The database is representative of the UK population in terms of demographic structure and prevalence of key comorbidities. ${ }^{36}$ Symptoms, examinations, and diagnoses in THIN are recorded using a hierarchical clinical coding system called Read codes. ${ }^{37}$ To improve data quality and reduce under-recording of events, general practices were included 12 months following instalment of electronic practice records or from the practice's acceptable mortality recording date. $^{38} 39$ The acceptable mortality reporting date for each practice is when the practice publishes mortality rates similar to the expected rate for their population outlined by the Office for National Statistics. ${ }^{38}$ A total of 8618829 patients were eligible to contribute during the study period. The data extraction and cohort selection was facilitated using the data extraction for epidemiological research (DExtER) tool. ${ }^{40}$ DExtER uses an extract, transform and load mechanism to extract study specific data with demonstrated reliability and validity. ${ }^{40}$

\section{Exposure and outcome definition}

The purpose of this study was to compare exposed patients (those with a general practitioner (GP) recorded code of a periodontal disease, defined as either gingivitis or periodontitis) to unexposed patients (those without such codes) and then calculate their risk of developing chronic diseases defined through Read codes. The chronic disease outcomes were categorised as: CVD (CVD composite measure; heart failure (HF), ischaemic heart disease (HF), stroke/transient-ischaemic attack, peripheral vascular disease), and vascular dementia), CMD (CMD composite measure; T2DM, and hypertension), AID (AID composite measure; T1DM, RA, systemic lupus erythematous, SS, vitiligo, psoriasis, pernicious anaemia, inflammatory bowel disease, coeliac disease, autoimmune thyroiditis, and scleroderma) and MIH (MIH composite; depression, anxiety and serious mental illness). In addition, this study examined the OR of having any chronic disease at the point of cohort entry (baseline) between the exposed and unexposed groups. 
Codes relating to exposure and outcomes were selected with the assistance of GPs, public health doctors and a periodontal specialist. Although, the IMRD-UK (previously named the THIN database) has been previously used to examine oral disorders such as temporomandibular joint disorders, ${ }^{41}{ }^{42}$ exposure code lists relating to gingivitis and periodontitis have never been previously validated. Outcome code lists included in this study have been used extensively in previously published work using the same database and many of the conditions included feature in the Quality Outcomes Framework. ${ }^{43-52}$ Read code lists relating to exposure terms and outcomes are provided in online supplemental eTable 1.

\section{Selection of unexposed group}

Each exposed patient was matched with up to four unexposed control patients from the remaining sample of patients in the dataset, who had no previously documented code relating to exposure. Controls were taken from a pool from eligible patients registered at a general practice within the same country of the UK and were matched by age at index date $( \pm 1$ year), sex, Townsend Deprivation Index ${ }^{53}$ and registration date $( \pm 12$ months). The Townsend score is a measure of material deprivation within a locality, incorporating information on unemployment, household overcrowding and car/home ownership $;^{53}$ a higher score indicates a greater level of socioeconomic deprivation.

\section{Follow-up period}

The index date for those in the exposed group was the date of the first Read code relating to exposure or when they became eligible to enter the study for those with a previous history of exposure (prevalent cases). Patients aged 18 years or older were eligible for entry into the cohort, therefore those who had the exposure of interest at an earlier age would enter the study as a prevalent case. To mitigate immortality time bias, ${ }^{54}$ the same index date was assigned to the corresponding unexposed patient. Immortality time bias refers to a period of follow-up where death or the study outcome cannot occur. The follow-up period for each patient was from the index date until the exit date. Exit date was defined as the earliest of the following end dates: study end date, last date of data collection from a given general practice, date patient transferred from general practice, date of death or date the outcome of interest occurred.

\section{Statistical analysis}

Categorical baseline data were described using proportions and continuous data described using means with SD. Missing data are highlighted in relevant baseline characteristic tables. Missing covariate data were treated as a separate missing category and included in the final analysis. Covariates considered in our modelling were selected due to their independent relationship with the outcome of interest or to remove any residual confounding. These included: age, sex, body mass index (BMI), Townsend
Deprivation Index (measured in quintiles), smoking status and ethnicity.

To describe the prevalence of chronic disease at baseline, we used logistic regression to estimate unadjusted OR and adjusted OR (aOR), following adjustment for key covariates (age categories, sex, BMI categories, Townsend deprivation index, smoking status categories and ethnicity categories). To calculate an incidence rate ((IR) per 1000 person-years) for each of the outcomes of interest, patients with pre-existing chronic disease were excluded to ensure the IR reflected outcomes which occurred following cohort entry. Cox regression accounting for person years of follow-up was then used to calculate a HR for each outcome of interest during the study period. Following adjustment for the covariates, we calculated and presented an aHR. ORs and HRs are presented with 95\% CIs with statistical significance set at $\mathrm{p}<0.05$.

An initial sensitivity analysis was conducted, isolating incident only cases (where the exposure occurred during the study period) compared with their respective controls. The purpose of this analysis was to exclude patients who may have had the exposure recorded prior to their study eligibility or study start date, leading to an unaccounted period where time dependent confounding factors may not have been sufficiently recorded in the patient's medical records. Throughout this paper we use the term periodontal disease to reflect the continuum from gingivitis to periodontitis though we conducted a second sensitivity analysis to examine if the outcomes differed when only examining cases with recorded periodontitis and their respective controls (exclusion of patients with a record of gingivitis and their respective controls). Stata V.15.1 SE software (StataCorp) was used to conduct all analyses.

\section{Patient and public involvement}

No patients were actively involved in setting the research question, outcome measures nor involved in the design of the study. Patients were not involved in interpretation or write up of the results, nor are there plans for the results to be disseminated to the patient community affected by this research.

\section{RESULTS}

\section{Study characteristics}

Of the eligible patients during the study period, we identified 64379 patients with a recorded history of a periodontal disease, of whom 60995 had gingivitis and 3384 had periodontitis, who were matched to 251161 unexposed patients. The median follow-up was similar in the two groups (exposed: 3.3 years, and unexposed: 3.5 years). The mean age at cohort entry was 44 years and $43 \%$ of the cohort were male. Due to matching, smoking status (30\% current smokers) and deprivation levels were similar between the groups. Additionally, BMI and ethnicity (despite $56 \%$ missing data) profiles were similar between the groups. Further details can be seen in table 1 . 
Table 1 Baseline characteristics of the study population

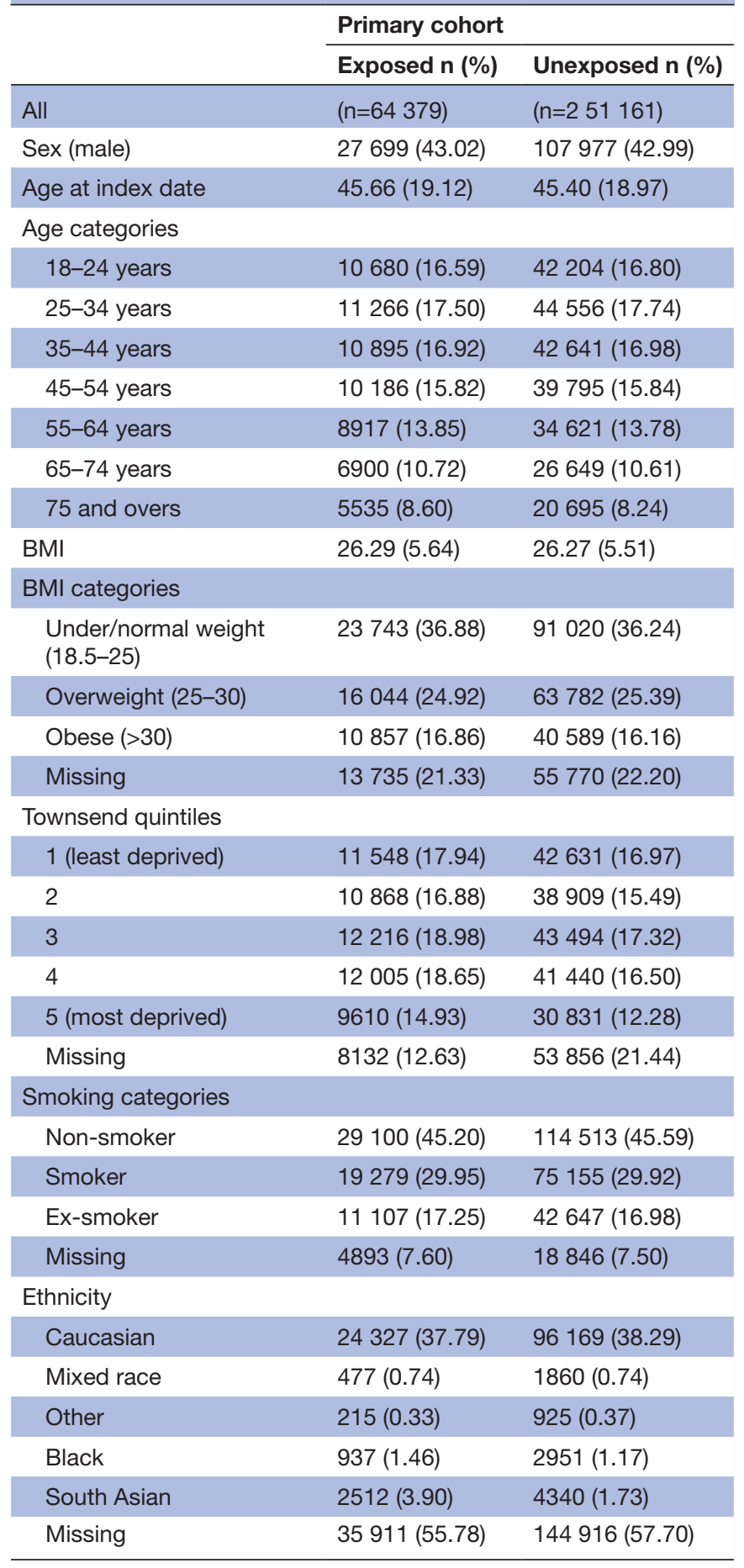

BMI, body mass index.

\section{Chronic disease at cohort entry}

At cohort entry there were 6355 patients $(9.9 \%)$ in the exposed group who had a diagnosis of CVD compared with $18594(7.4 \%)$ in the unexposed group. Following adjustment for covariates this translated to an aOR of 1.43 (95\% CI 1.38 to 1.48). When examining CMD, 12 321 patients $(19.1 \%)$ in the exposed group had a diagnosis of CMD at cohort entry compared with 42828 $(17.1 \%)$ in the unexposed group. This translated into an aOR of 1.16 (95\% CI 1.13 to 1.19 ), and the association with the presence of T2DM (aOR 1.23; $95 \%$ CI 1.18 to 1.28 ) was notable. With AID, 5265 patients $(8.2 \%)$ in the exposed group had a diagnosis of AID at cohort entry compared with $15690(6.3 \%)$ in the unexposed group equating to an aOR of 1.33 (95\% CI 1.28 to 1.37). Lastly, MIH was seen to have the greatest OR (aOR 1.79; 95\% CI 1.75 to 1.83 ) with periodontal disease at cohort entry with 19142 patients (29.7\%) in the exposed group who had a diagnosis of AID at cohort entry compared with $48998(19.5 \%)$ in the unexposed group. Further results can be seen in table 2 and figure 1.

\section{The risk of developing subsequent chronic disease}

During the study period, there were 3104 (5.4\%) new diagnoses of CVD in the exposed cohort equating to an IR of 8.2 per 1000 person-years compared with 7.3 per 1000 person-years (10 $439(4.5 \%)$ new recorded diagnoses) in the unexposed cohort. This translated to an aHR of 1.18 (95\% CI 1.13 to 1.23$)$. When examining CMD, there were 5005 (9.6\%) new diagnoses of CMD in the exposed cohort equating to an IR of 15.5 per 1000 person-years compared with 14.6 per 1000 person-years (17 822 (8.6\%) new recorded diagnoses) in the unexposed cohort. Ultimately this translated into an aHR of 1.07 (95\% CI 1.03 to 1.10 ) where the risk was highest for the development of T2DM (aHR $1.26 ; 95 \%$ CI 1.21 to 1.32 ). When examining AID, there were 1945 (3.3\%) new diagnoses of AID in the exposed cohort equating to an IR of 5.8 per 1000 person-years compared with 4.3 per 1000 person-years (5674 (2.4\%) new recorded diagnoses) in the unexposed cohort. This translated into an aHR of 1.33 (95\% CI 1.26 to 1.40 ). Finally, with MIH, there were $5296(11.7 \%)$ new diagnoses of MIH in the exposed cohort relating to an IR of 19.2 per 1000 person-years compared with 14.2 per 1000 person-years (16 758 $(8.3 \%)$ new recorded diagnoses) in the unexposed cohort. This translated into an aHR of 1.37 (95\% CI 1.33 to 1.42 ). Further details can be seen in table 3 and figure 2 .

\section{Sensitivity analysis: incident only cohort}

Of the total exposed cohort, 31968 (49.7\% of total exposed cohort) patients had an exposure code entered during the study period (incident cohort) and were matched to 126278 (50.3\% of total unexposed cohort) unexposed cohort (baseline characteristics are described in online supplemental eTable 2. The median follow-up in this cohort was 3.4 years. The average age was 49 years, $43 \%$ of cohort were male and the proportion of obese patients, current smokers and deprivation quintiles were similar with the primary analysis.

In the incident only sensitivity analysis, the OR of having chronic disease were similar to the primary cohort. There was an increased aOR of having CVD 


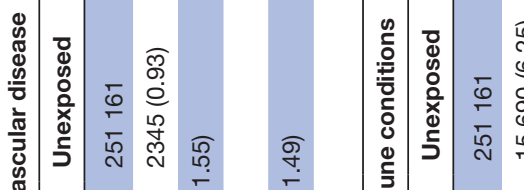

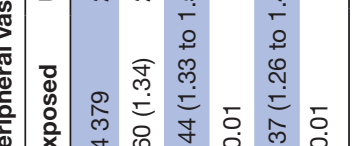

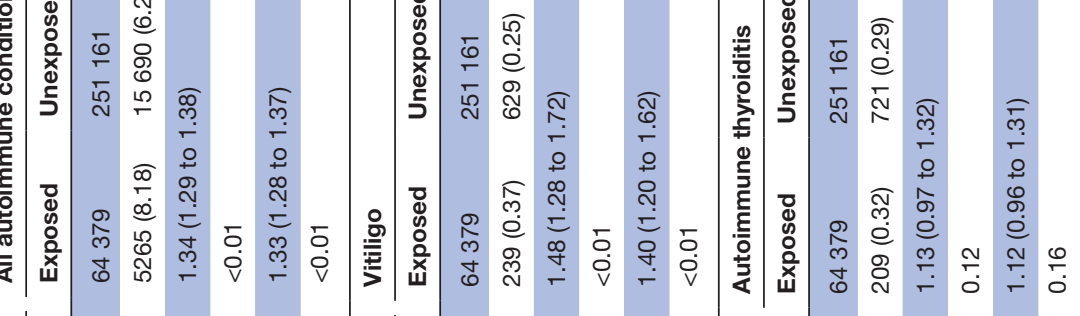

苞

\$

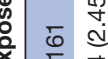

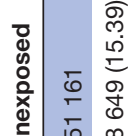

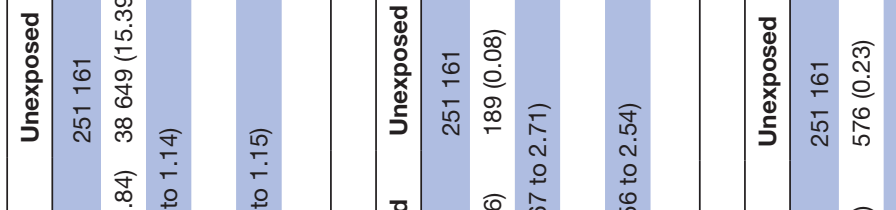

至

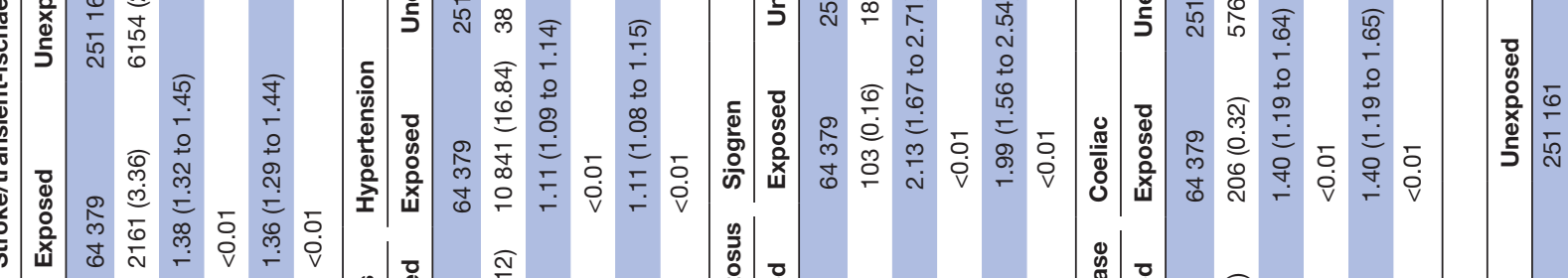

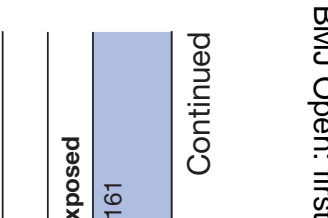

$\stackrel{\overrightarrow{7}}{\stackrel{\vec{P}}{+}}$

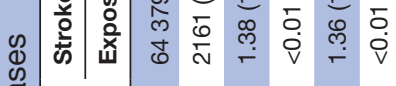

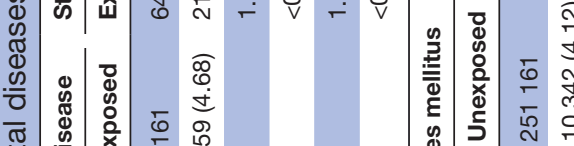

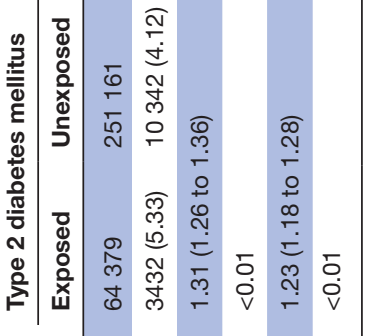

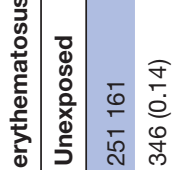

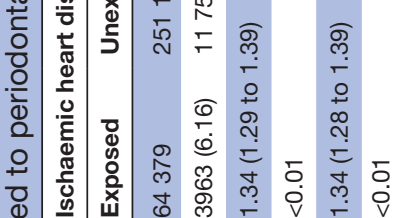

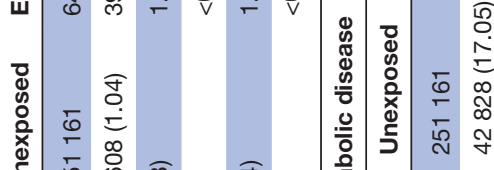

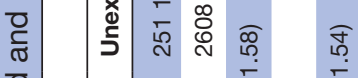

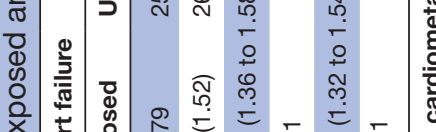

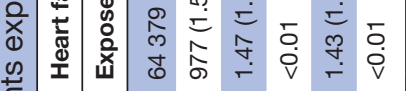

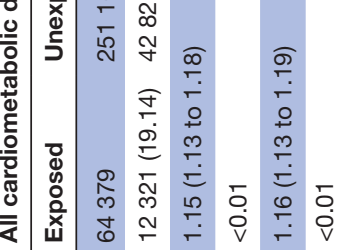

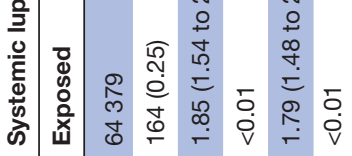

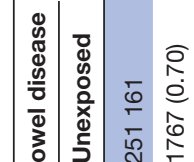

兽

焉

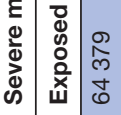

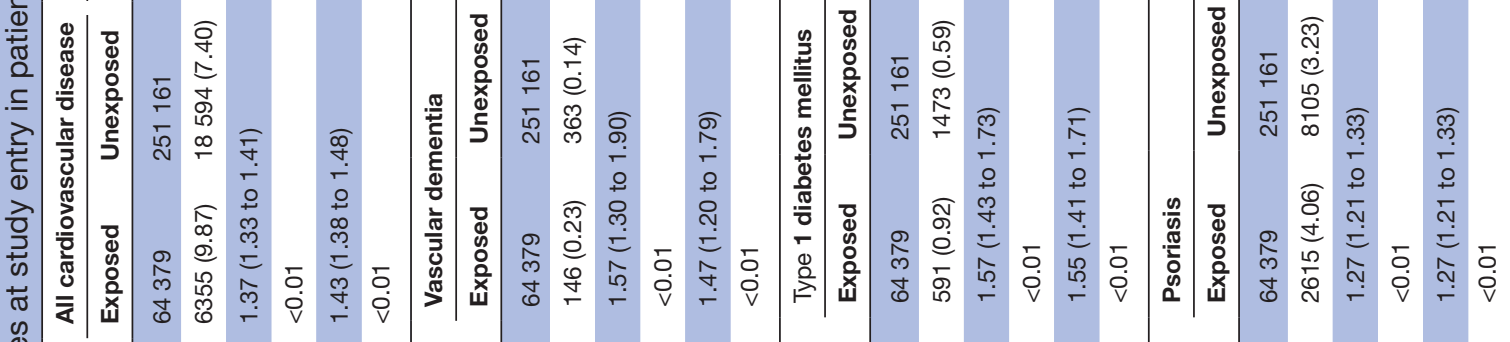

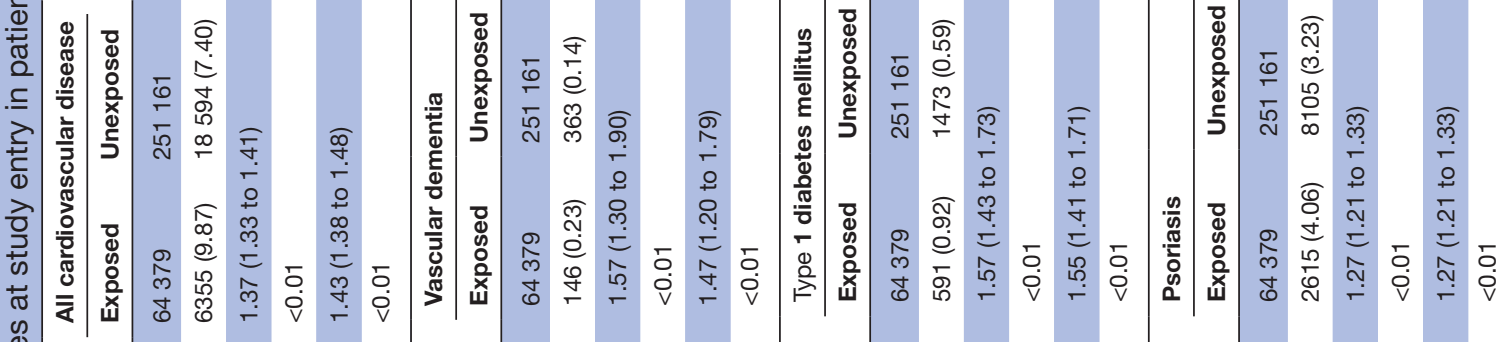

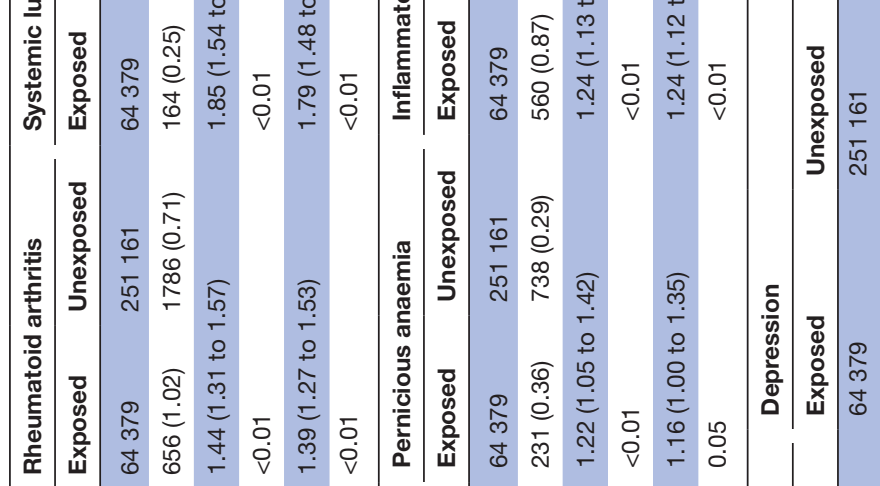

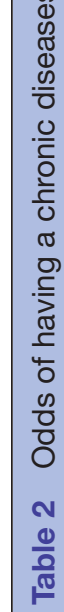
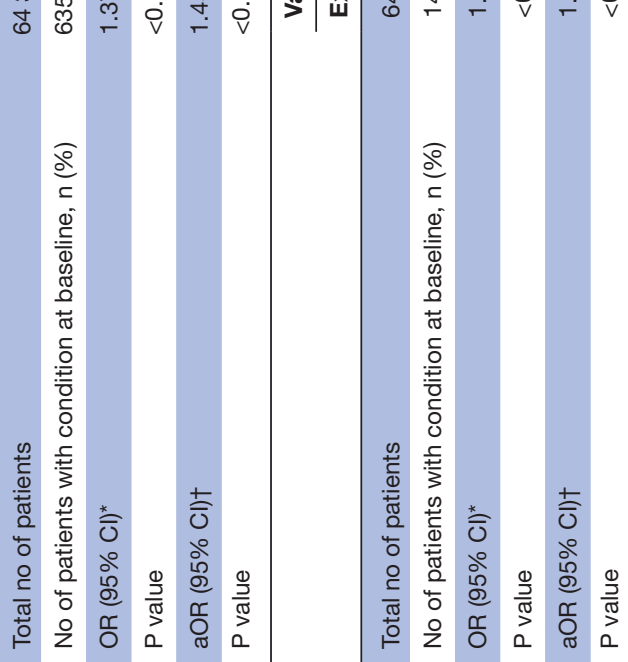

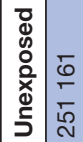

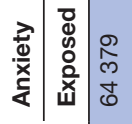

尺

品

○

$\overrightarrow{0}$

品

$\frac{\mathbb{D}}{3}$

กิ

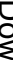

$\sum_{\overline{0}}^{\circ}$

$\stackrel{0}{\circ}$

흑

往

흔

$\frac{0}{8}$

3

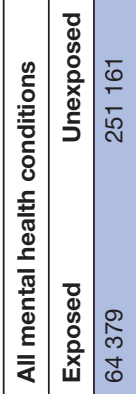

을

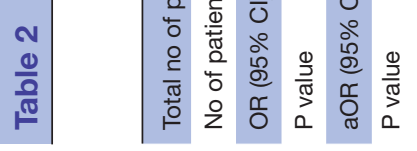
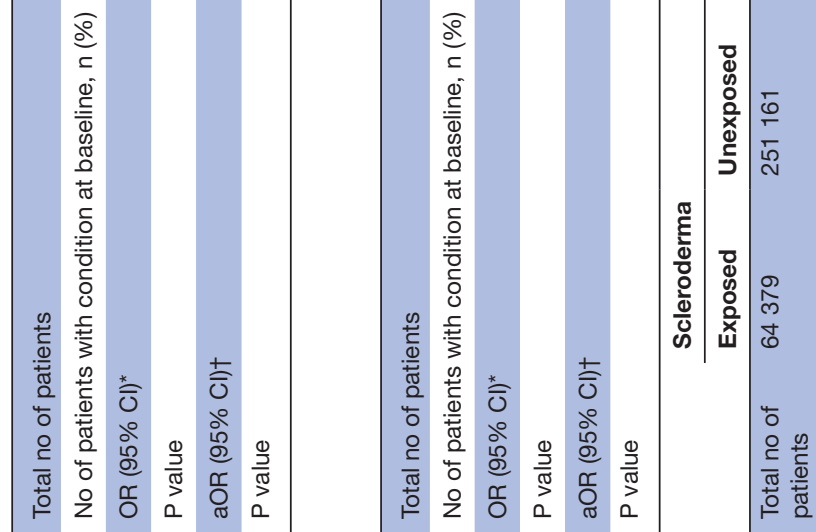


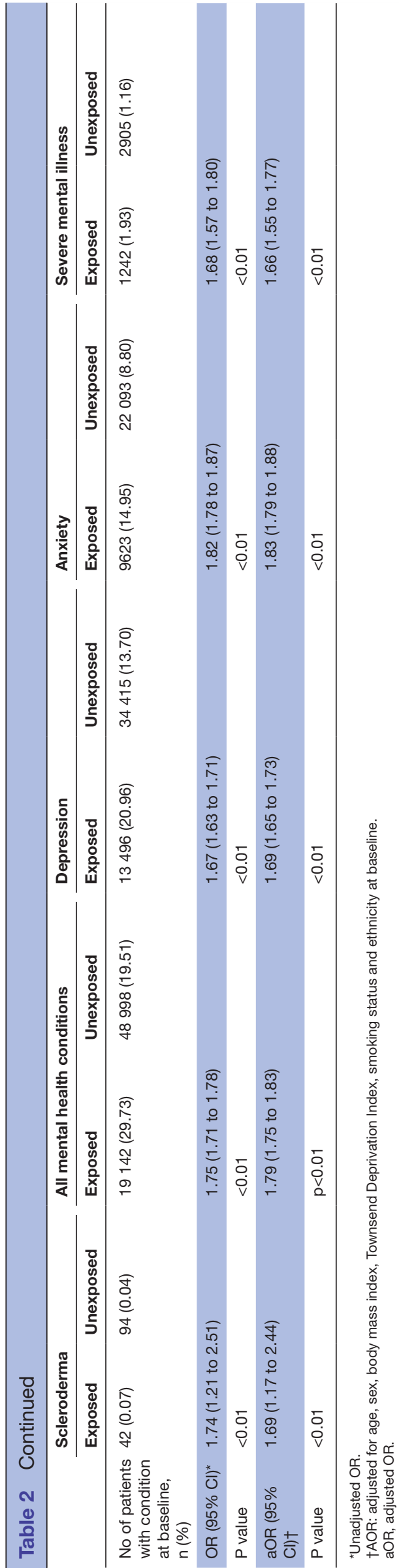

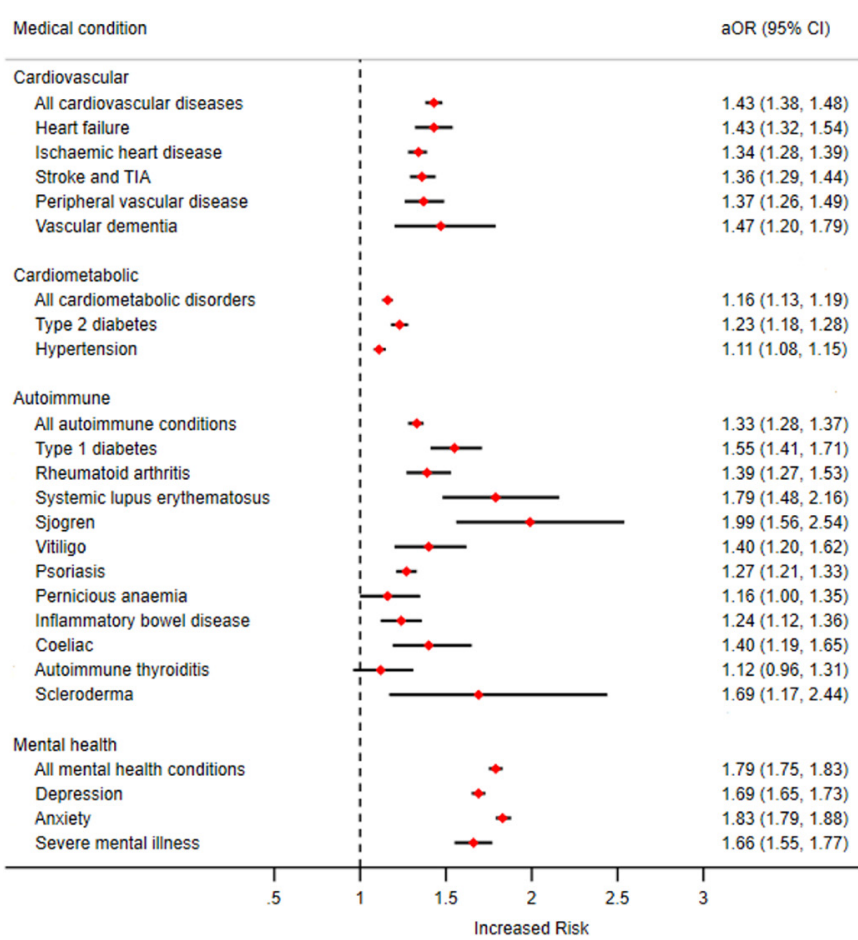

Figure 1 Odds of having chronic diseases at study entry in patients exposed and unexposed to periodontal diseases. $\mathrm{aOR}$, adjusted odds ratio; TIA, transient ischemic attack.

(1.42; $95 \%$ CI 1.36 to 1.49$)$, CMD (1.14; $95 \%$ CI 1.10 to 1.19$)$, AID $(1.26 ; 95 \%$ CI 1.21 to 1.32$)$ and $\mathrm{MIH}$ (1.71; $95 \%$ CI 1.66 to 1.76$)$. Further details in online supplemental eTable 3 . When examining subsequent disease outcomes, there also remained an increased risk (described as an aHR) of developing CVD (1.17; $95 \%$ CI 1.10 to 1.24$)$, CMD $(1.07 ; 95 \%$ CI 1.02 to 1.12), AID (1.48; 95\% CI 1.37 to 1.59$)$ and MIH (1.47; $95 \%$ CI 1.40 to 1.53$)$. Further details in online supplemental eTable 4.

\section{Sensitivity analysis: periodontitis only cohort}

When restricting the analysis to only those with periodontitis, the exposed cohort of 3384 patients $(5.3 \%$ of the total exposed group) were matched to 12893 patients (5.1\% of the unexposed group). The median follow-up in this cohort was 3.6 years. The average age was 48 years, $46 \%$ of cohort were male and the proportion of other baseline characteristics were also similar to the primary analysis. Further details in online supplemental eTable 5.

In this analysis, the OR of having chronic disease were similar to the primary cohort. There was an increased aOR of having CVD (1.50; 95\% CI 1.30 to $1.74)$, CMD (1.19; $95 \%$ CI 1.06 to 1.34 ), AID (1.32; $95 \%$ CI 1.15 to 1.52$)$ and MIH $(1.63 ; 95 \%$ CI 1.49 to $1.78)$. Further details can be seen in online supplemental eTable 6 . When examining subsequent disease outcomes, an increased risk (aHR) remained for developing CVD (1.31; 95\% CI 1.12 to 1.52$)$ and $\mathrm{MIH}$ (1.33; $95 \%$ CI 1.16 to 1.52 ) but not for CMD (0.96; $95 \%$ CI 0.85 to 1.10$)$ and AID (1.21; 95\% CI 0.96 to 
㻤

অ.

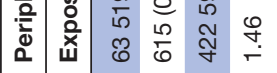

苍

焉

$\mathscr{\infty}$

क

焉

응

离

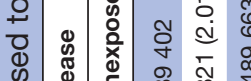

范

希

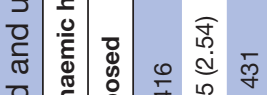

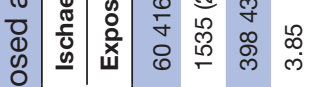

की

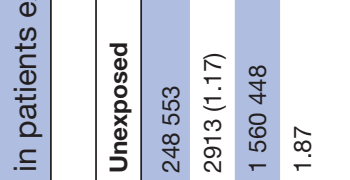

年

.क्)

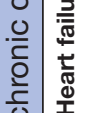

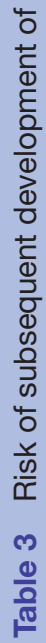

先

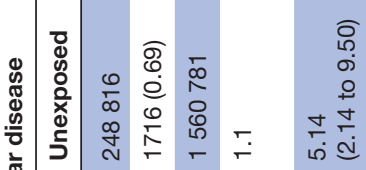

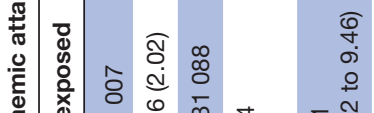

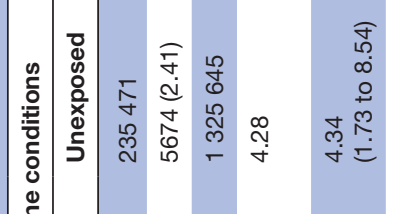

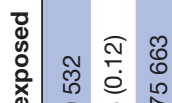

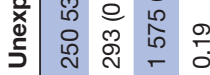

in

हो ब ब

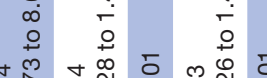

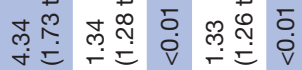

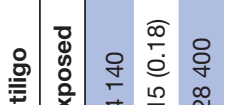

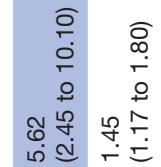

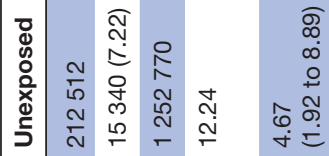

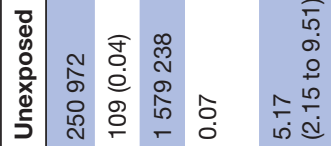

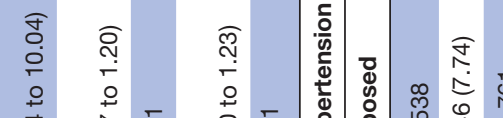

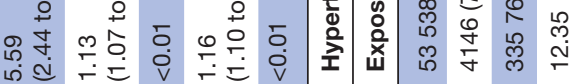

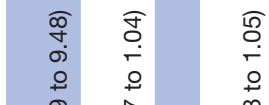

ம்

离

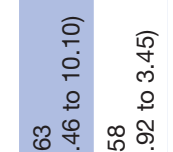

ถึำ

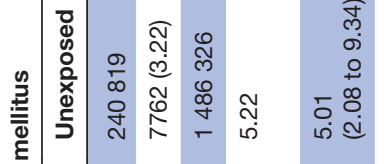

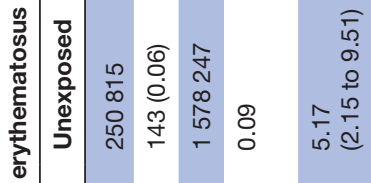

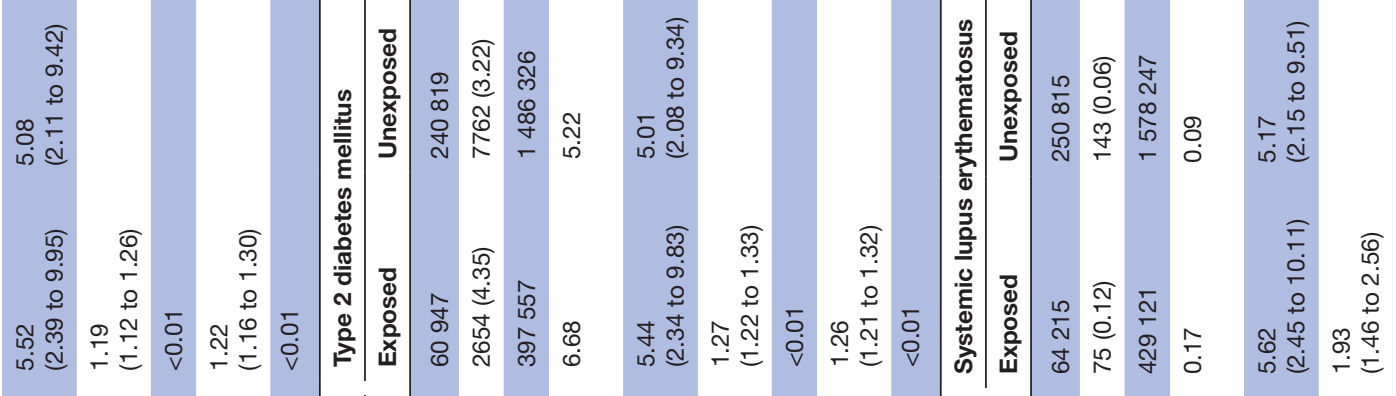

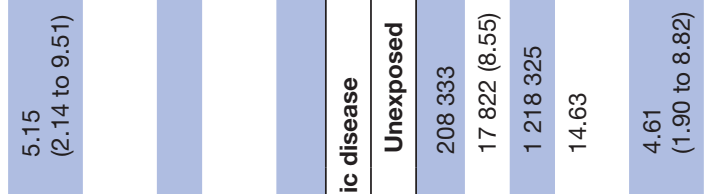

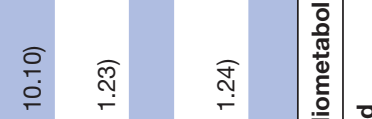

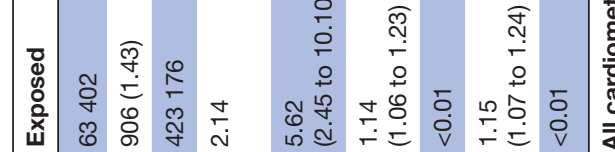

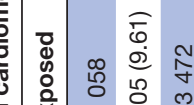

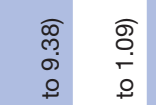

움

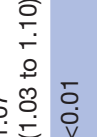

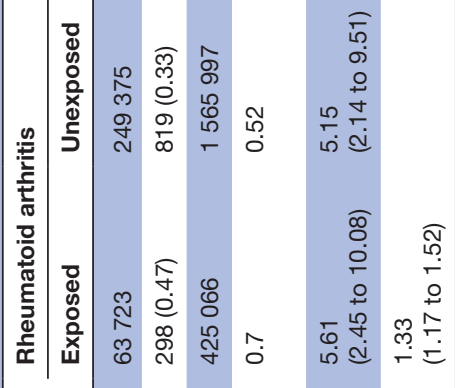

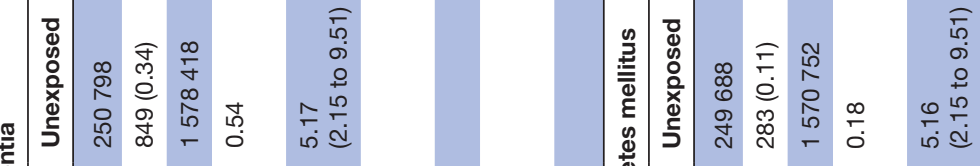

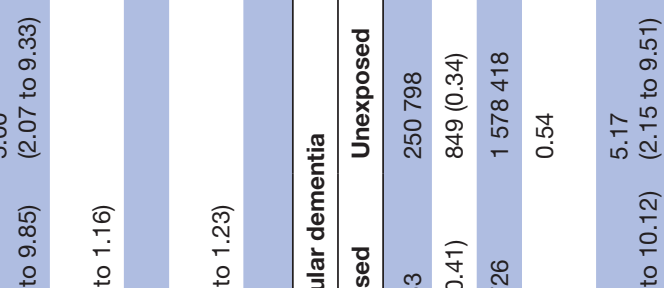

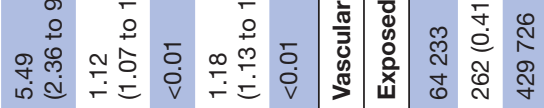

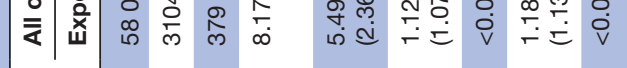

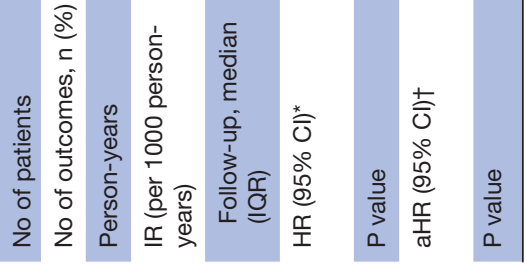

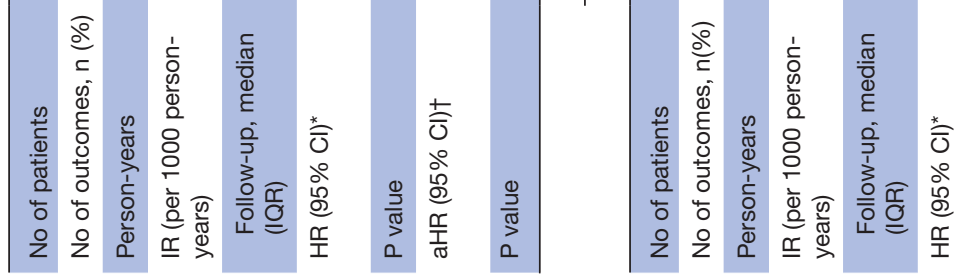




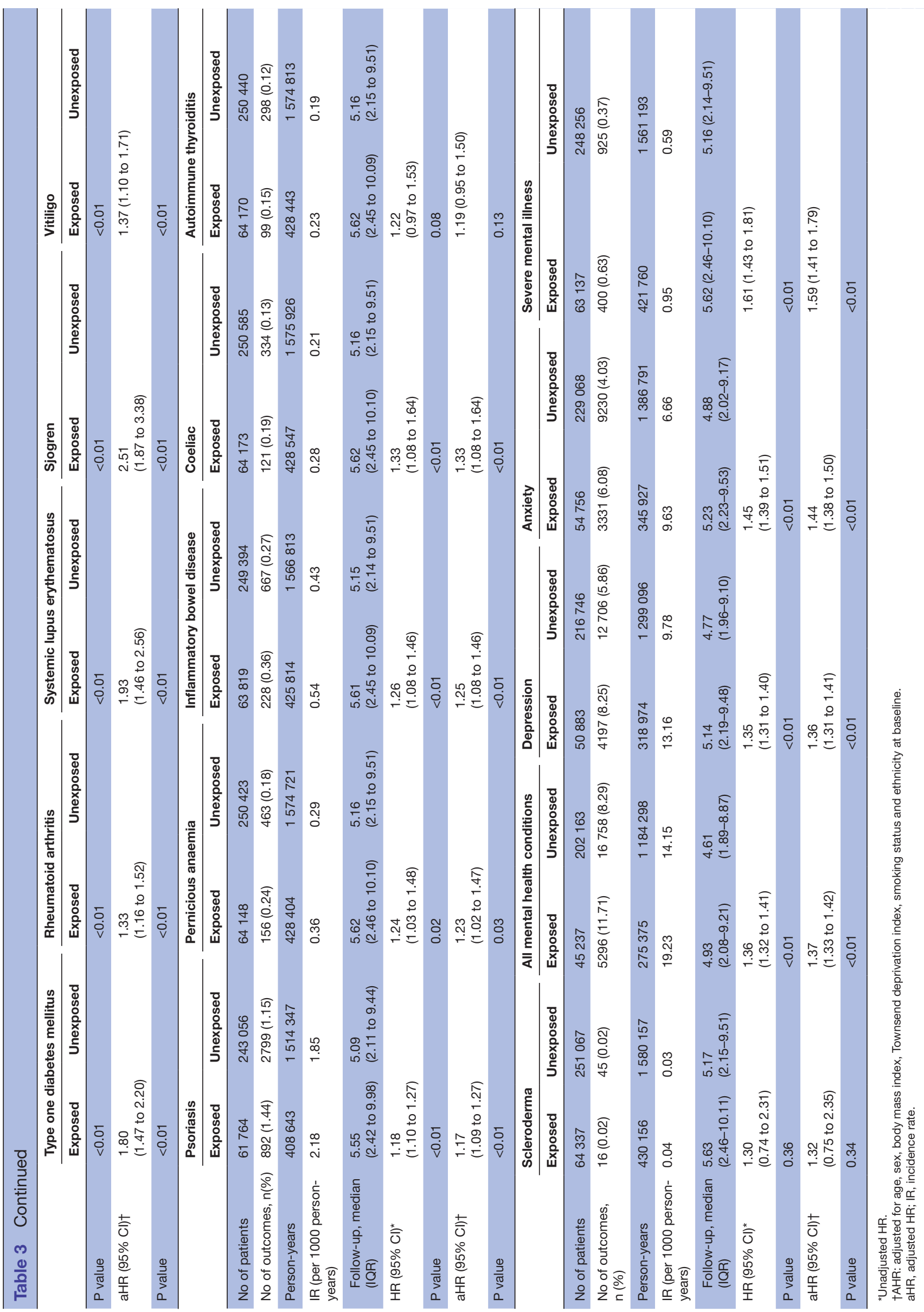




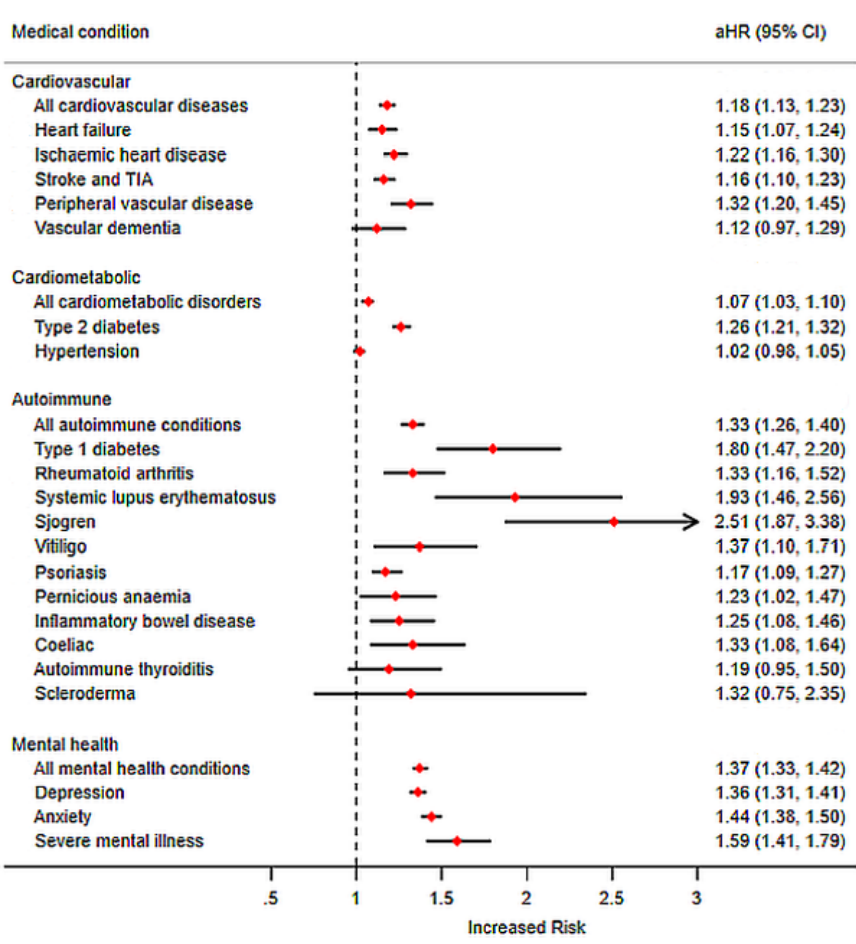

Figure 2 Risk of subsequent development of chronic diseases in patients exposed and unexposed to periodontal diseases. aHR, adjusted hazard ratio; TIA, transient ischemic attack.

1.51). Further details demonstrated in online supplemental eTable 7 .

\section{DISCUSSION}

\section{Summary of key results}

To our knowledge, this is the first attempt to synthesise data exploring the relationship between periodontal diseases and the development of chronic disease in a UK retrospective cohort derived from medical records. Our study demonstrates that the presence of a GP recorded diagnosis of a periodontal disease is moderately associated with an $18 \%, 7 \%$ (Although $26 \%$ risk of T2DM), $33 \%$ and $37 \%$ increased risk of CVD, CMD, AID and MIH, respectively. This risk persisted when analysing patients who were diagnosed with a periodontal disease during the study period. However, in patients specifically with periodontitis, this risk was not evident for CMD or AID.

\section{Results in context of current literature}

To date, research evaluating the association between periodontal diseases and systemic health has focused on periodontitis, rather than gingivitis, due to the more extensive inflammatory process and thus the potential for greater systemic effects.

This study concurs with the extensive literature highlighting the association of atherosclerotic diseases with periodontal disease. Humphrey et al, demonstrated a risk ratio of 1.24 (95\% CI 1.01 to 1.51 ) of a CVD/CHD event in the presence of periodontitis. ${ }^{55}$ More recently a systematic review by Dietrich et al, demonstrated there was an increased risk of CVD when considering various periodontal disease measures ranging from probing pocket depth measurements to radiographic assessments of bone levels. ${ }^{56}$ For those studies where severe periodontitis was the exposure, the associations with CVD were stronger than in our study. This may be due to limitations in our coding, whereby we were unable to classify the severity of periodontitis.

There are several potential mechanisms explaining the increase in atherosclerosis in patients with periodontitis. First, transient bacteraemia in patients with periodontitis may be pathogenic. ${ }^{57}$ Furthermore, periodontitis patients have elevated circulating levels of pro-inflammatory mediators implicated in atherosclerosis. ${ }^{58}$ There is robust evidence that treatment of periodontitis improves markers of systemic inflammation and surrogate markers of CVD risk such as flow-mediated dilatation. ${ }^{59} 60$

T2DM demonstrates a bidirectional relationship with periodontitis, that is, poorly controlled diabetes is a risk factor for periodontitis and periodontitis itself impacts the diabetes disease process. A systematic review commissioned by the International Diabetes Federation and $\mathrm{EFP}^{61}$ concluded that individuals with periodontitis have a greater risk of developing T2DM with a HR 1.19-1.33 which is in agreement with the increased aHR demonstrated in this study. Literature also exists investigating the impact of periodontal therapy on diabetic outcomes. A recent review demonstrates reductions in HbAlc $\left(-0.40 \%\right.$ at 3 months) following periodontal therapy ${ }^{62}$ Evidence suggests appropriate targeted screening in dental settings may successfully identify cases of undiagnosed diabetes. ${ }^{63}{ }^{64}$ Within the UK there is a drive to use the dental team in identifying and managing T2DM, evident by the recent publication of the National Health Service England Commissioning Standard 'Dental Care for People with Diabetes. ${ }^{65}$ This document proposes a formalised pathway between general medical practitioner and dentist on diagnosis of T2DM.

While the evidence base for T2DM is long established, there is limited evidence that T1DM demonstrates a similar relationship. Systematic reviews conducted in 2013 and 2018 were unable to find any studies that met eligibility criteria investigating the association between periodontal health and T1DM. ${ }^{6166}$ The reason for this may be that the age of periodontal disease diagnosis is typically much older than the age of T1DM diagnosis which limits the available data to answer such a question. Our study suggests an increased risk for incident T1DM in patients with a periodontal disease (aHR 1.80; 95\% CI 1.47 to 2.20 ) but was not clearly evident when considering only those patients with periodontitis (aHR 1.62; 95\% CI 0.70 to 3.76 ).

The mechanisms connecting mental health with periodontal inflammation include both behavioural and immunological. Existing literature focuses on depression and anxiety as risk factors for periodontitis. Individuals under increased stress may reduce health promoting behaviours (eg, optimal oral hygiene practices) and 
instead be driven towards detrimental health behaviours (eg, smoking). The research linking depression as a risk factor for periodontitis has been contradictory. ${ }^{67}$

Conversely, studies assessing mental health outcomes consequent on periodontal diseases are sparse. Potential mechanisms underlying such a relation include psychological mechanisms with outcomes of periodontal diseases (eg, halitosis, loss of teeth, drifting of teeth) impacting negatively on social and functional aspects of life, thus impacting on mood. One study used the well-established EuroQoI questionnaire to review oral health in relation to anxiety/depression. In 10\% of individuals with increased probing pocket depth $(\geq 6 \mathrm{~mm})$ anxiety/depression was experienced $25 \%$ of the time. ${ }^{68}$ Our study demonstrates a significantly increased risk of all mental health illnesses in patients with a periodontal disease (aOR 1.79; 95\% CI 1.75 to 1.83 ) and an increased risk of developing a mental health condition (aHR $1.37 ; 95 \%$ CI 1.33 to 1.42 ). While severe mental illness in particular did not demonstrate a significant increase in the incident only analysis of the periodontitis cohort, we found that individuals with periodontitis have a $37 \%$ increased risk of developing anxiety. Furthermore, within the same periodontitis cohort there was a significantly higher risk of developing depression (aHR 1.29; 95\% CI 1.11 to 1.50). This provides further evidence for the potential psychosocial impact of periodontal diseases and an issue that is under-reported in the literature.

Of the autoimmune conditions included within our analysis, the one most frequently reported in the context of periodontitis is RA. A number of mechanisms have been proposed linking the periodontium with the progression of RA. For example Porphyromonas gingivalis, expresses peptidyl arginine deiminases, which drive protein citrullination. Exposure to citrullinated proteins in periodontitis patients may then lead to the generation of anticitrullinated protein antibodies, stimulating a systemic autoimmune response characteristic of RA. ${ }^{33} \mathrm{~A}$ study analysing the third US National Health and Nutrition Examination Survey III identified that individuals with RA were more likely to present with both periodontitis (OR 1.82; 95\% CI 1.04 to 3.20) and edentulism (OR $2.27 ; 95 \%$ CI 1.56 to 3.31$){ }^{69}$ Our data support an association between periodontal diseases and development of RA. For periodontitis alone, the increased risk of RA at baseline approached significance, although no significant risk was identified for subsequent development of RA. This may be attributed to the low number of outcomes during this subset analysis and is in agreement with a previous study based on the Taiwanese National Health Insurance Research Database. ${ }^{70}$ The Taiwanese study also demonstrated an increased risk of developing SS in patients with chronic periodontitis (HR 1.87; 95\% CI 1.64 to 2.13.) ${ }^{71}$ Our study also demonstrates the most substantial increased risk ratio was seen in the development of SS in those with periodontal diseases (HR 2.51; 95\% CI 1.87 to 3.38 ), with the periodontitis only cohort showing a substantial increased HR; however, the low number of outcomes means that the results must be interpreted with caution (aHR 6.67; 95\% CI 1.66 to 26.86). Despite these significant findings, the pathophysiology explaining this relationship is well understood. It is apparent that both conditions may present with xerostomia leading to bacterial overgrowth in the oral cavity and over expression of proinflammatory cytokines which may in turn act as risk factors for either periodontal disease or SS progression. ${ }^{32}$ In addition to the known relationship between successful periodontal treatment and glycaemic management, there is an emerging field of literature identifying that periodontal treatment can lower levels of oral bacteria and circulating inflammatory markers. ${ }^{72}$ Although, the relevance on how this relationship may translate into clinical endpoints such as the reduced incidence of chronic conditions is still unclear and requires further research.

\section{LIMITATIONS}

The primary limitation is that the validity of the results rely on the accuracy of documentation by the healthcare professionals contributing to the dataset. To date, the accuracy of oral health read codes in primary care datasets have not been validated. ${ }^{73}$ However, it is important to highlight that in the UK GPs are not usually the professionals responsible for diagnosing periodontal disease and this is typically identified by dental practitioners based on a clinical examination. Periodontal Read codes are thus likely to be inputted following receipt of clinical letters from dental healthcare professional, though GP diagnosis (more likely for gingivitis) and self-report are also possibilities. Overall, it is likely that there is under recording of periodontal diseases in this data set that is, it is likely that patients with a periodontal disease are not recorded as having it. Therefore, it is possible our findings may not reflect the true effect size and are likely to be an underestimate. On the other hand, selective recording of severe periodontal disease might have led to an overestimation of the true effect size.

\section{CONCLUSION}

In conclusion, this study demonstrates that periodontal diseases (including gingivitis and periodontitis) are moderately associated with an increased risk of developing cardiovascular, CMD, AID and MIH; and these were statistically significant. With this in mind, it is important to highlight patients with periodontal diseases and to tackle risk factors to prevent the development and progression of such conditions. It is imperative that preventative approaches, including those aimed at preventing and detecting gingival inflammation and its associated consequences, and improved communication between medical and dental teams, are implemented to reduce the risk of ill health. We also stress the importance of improving dental coding as per the 2017 periodontal classification system in general practice settings to support holistic patient care and oral epidemiological 
research. ${ }^{74}$ An important implication of our findings is the need for effective communication between dental and other healthcare professionals to ensure patients obtain an effective treatment plan targeting both oral and extraoral health to improve current health and reduce the risk of future ill health.

\section{Author affiliations}

${ }^{1}$ Institute of Applied Health Research, University of Birmingham College of Medical and Dental Sciences, Birmingham, UK

${ }^{2}$ Birmingham Dental Hospital, Birmingham, UK

${ }^{3}$ The Newcastle Upon Tyne Hospitals NHS Foundation Trust, Newcastle, UK

${ }^{4}$ Population Health Sciences, Newcastle University, Newcastle, UK

${ }^{5}$ Kennedy Institute of Rheumatology, University of Oxford, Oxford, UK

${ }^{6}$ Institute of Inflammation and Ageing, University of Birmingham College of Medical and Dental Sciences, Birmingham, UK

${ }^{7}$ Sandwell and West Birmingham NHS Trust, Birmingham, UK

${ }^{8}$ Research into Inflammatory Arthritis Centre Versus Arthritis and MRC- Versus

Arthritis Centre for Musculoskeletal Ageing Research, Birmingham, UK

Twitter Dawit T Zemedikun @Dawit_TZ, Joht Singh Chandan @johtchandan and Marie Falahee @DrMarieFalahee

Acknowledgements Professor Thomas Dietrich kindly also reviewed and commented on a finalised copy of the manuscript.

Contributors DTZ, JSC, DR, TT, KN and KR conceived the idea for the study. DTZ, KMG and JSC conducted the statistical analysis. DTZ, JSC, DR and ADR were responsible for the initial draft of the report. KMG, TT, MF, PDP, JML, KR and KN contributed to subsequent drafts and all authors were involved in the final draft. $\mathrm{KR}$ and $\mathrm{KN}$ were responsible for supervision. JSC acts as guarantor for the final manuscript.

Funding This paper represents independent research part funded by the MRC Versus Arthritis Centre for Musculoskeletal Ageing Research. KR and JL are supported by the NIHR Birmingham Biomedical Research Centre.

Competing interests None declared.

Patient consent for publication Not applicable.

Ethics approval Anonymised data were used throughout the study provided by the data provider to the University of Birmingham. Studies using IMRD-UK database have had initial ethical approval from the NHS South-East Multicentre Research Ethics Committee, subject to prior independent scientific review. The Scientific Review Committee (IQVIA) approved the study protocol (SRC Reference Number: SRC20THIN036).

Provenance and peer review Not commissioned; externally peer reviewed.

Data availability statement Data may be obtained from a third party and are not publicly available. The full data-set and statistical analysis code following receipt of ethics approval are available from author JSC (joht.chandan@nhs.net).

Supplemental material This content has been supplied by the author(s). It has not been vetted by BMJ Publishing Group Limited (BMJ) and may not have been peer-reviewed. Any opinions or recommendations discussed are solely those of the author(s) and are not endorsed by BMJ. BMJ disclaims all liability and responsibility arising from any reliance placed on the content. Where the content includes any translated material, BMJ does not warrant the accuracy and reliability of the translations (including but not limited to local regulations, clinical guidelines, terminology, drug names and drug dosages), and is not responsible for any error and/or omissions arising from translation and adaptation or otherwise.

Open access This is an open access article distributed in accordance with the Creative Commons Attribution Non Commercial (CC BY-NC 4.0) license, which permits others to distribute, remix, adapt, build upon this work non-commercially, and license their derivative works on different terms, provided the original work is properly cited, appropriate credit is given, any changes made indicated, and the use is non-commercial. See: http://creativecommons.org/licenses/by-nc/4.0/.

\section{ORCID iDs}

Dawit T Zemedikun http://orcid.org/0000-0003-3642-0456

Joht Singh Chandan http://orcid.org/0000-0002-9561-5141

Marie Falahee http://orcid.org/0000-0001-5928-486X

Janet M Lord http://orcid.org/0000-0003-1030-6786

\section{REFERENCES}

1 GBD 2017 Disease and Injury Incidence and Prevalence Collaborators. Global, regional, and national incidence, prevalence, and years lived with disability for 354 diseases and injuries for 195 countries and territories, 1990-2017: a systematic analysis for the global burden of disease study 2017. Lancet 2018;392:1789-858.

2 Kinane DF, Stathopoulou PG, Papapanou PN. Periodontal diseases. Nat Rev Dis Primers 2017;3:1-14.

3 Centers for Disease Control and Prevention. Periodontal disease, 2013. Available: https://www.cdc.gov/oralhealth/conditions/ periodontal-disease.html [Accessed 30 Sep 2020].

4 Mombelli A, Casagni F, Madianos PN. Can presence or absence of periodontal pathogens distinguish between subjects with chronic and aggressive periodontitis? A systematic review. J Clin Periodontol 2002;29 Suppl 3:10-21.

5 Kinane DF, Demuth DR, Gorr S-U, et al. Human variability in innate immunity. Periodontol 2000 2007;45:14-34.

6 Hajishengallis G, Lamont RJ. Beyond the red complex and into more complexity: the polymicrobial synergy and dysbiosis (PSD) model of periodontal disease etiology. Mol Oral Microbiol 2012;27:409-19.

7 Gift HC, Reisine ST, Larach DC. The social impact of dental problems and visits. Am J Public Health 1992;82:1663-8.

8 Slade GD. Measuring oral health and quality of life. Chapel Hill, 1997.

9 Miller AH, Raison CL. The role of inflammation in depression: from evolutionary imperative to modern treatment target. Nat Rev Immunol 2016;16:22-34

10 Dantzer R, O'Connor JC, Lawson MA, et al. Inflammation-Associated depression: from serotonin to kynurenine. Psychoneuroendocrinology 2011;36:426-36.

11 Fan X, Goff DC, Henderson DC. Inflammation and schizophrenia. Expert Rev Neurother 2007;7:789-96.

12 Calle MC, Fernandez ML. Inflammation and type 2 diabetes. Diabetes Metab 2012;38:183-91.

13 Berg AH, Scherer PE. Adipose tissue, inflammation, and cardiovascular disease. Circ Res 2005;96:939-49.

14 GBD 2017 Causes of Death Collaborators. Global, regional, and national age-sex-specific mortality for 282 causes of death in 195 countries and territories, 1980-2017: a systematic analysis for the global burden of disease study 2017. Lancet 2018;392:1736-88.

15 Makkar H, Reynolds MA, Wadhawan A, et al. Periodontal, metabolic, and cardiovascular disease: exploring the role of inflammation and mental health. Pteridines 2018;29:124-63.

16 Chandan JS, Thomas T. The impact of inflammatory bowel disease on oral health. Br Dent J 2017;222:549-53.

17 Thomas T, Chandan JS. Multidisciplinary management: inflammatory bowel disease. Br Dent J 2017;222:4-5.

18 Linden GJ, Linden K, Yarnell J, et al. All-Cause mortality and periodontitis in 60-70-year-old men: a prospective cohort study. J Clin Periodontol 2012;39:940-6.

19 Kinane DF, Chestnutt IG. Smoking and periodontal disease. Crit Rev Oral Biol Med 2000;11:356-65.

20 Kassebaum NJ, Bernabé E, Dahiya M, et al. Global burden of severe periodontitis in 1990-2010: a systematic review and meta-regression. J Dent Res 2014;93:1045-53.

21 Eke PI, Wei L, Thornton-Evans GO, et al. Risk indicators for periodontitis in US adults: NHANES 2009 to 2012. J Periodontol 2016;87:1174-85.

22 Eke PI, Dye BA, Wei L, et al. Prevalence of periodontitis in adults in the United States: 2009 and 2010. J Dent Res 2012;91:914-20.

23 Lockhart PB, Bolger AF, Papapanou PN, et al. Periodontal disease and atherosclerotic vascular disease: does the evidence support an independent association?: a scientific statement from the American heart association. Circulation 2012;125:2520-44.

24 Lafon A, Pereira B, Dufour T, et al. Periodontal disease and stroke: a meta-analysis of cohort studies. Eur J Neurol 2014;21:1155-67.

25 Leng W-D, Zeng X-T, Kwong JSW, et al. Periodontal disease and risk of coronary heart disease: an updated meta-analysis of prospective cohort studies. Int J Cardiol 2015;201:469-72.

26 Sanz M, Marco Del Castillo A, Jepsen S, et al. Periodontitis and cardiovascular diseases: consensus report. J Clin Periodontol 2020;47:268-88.

27 D'Aiuto F, Gkranias N, Bhowruth D, et al. Systemic effects of periodontitis treatment in patients with type 2 diabetes: a 12 month, single-centre, investigator-masked, randomised trial. Lancet Diabetes Endocrinol 2018:6:954-65.

28 Seitz MW, Listl S, Bartols A, et al. Current knowledge on correlations between highly prevalent dental conditions and chronic diseases: an umbrella review. Prev Chronic Dis 2019;16:180641.

29 Engebretson S, Kocher T. Evidence that periodontal treatment improves diabetes outcomes: a systematic review and metaanalysis. J Clin Periodontol 2013;40 Suppl 14:S153-63. 
30 D'Aiuto F, Gable D, Syed Z, et al. Evidence summary: the relationship between oral diseases and diabetes. Br Dent J 2017;222:944-8.

31 Bingham CO, Moni M. Periodontal disease and rheumatoid arthritis: the evidence accumulates for complex pathobiologic interactions. Curr Opin Rheumatol 2013;25:345-53.

32 Lin C-Y, Tseng C-F, Liu J-M, et al. Association between periodontal disease and subsequent sjögren's syndrome: A nationwide population-based cohort study. Int J Environ Res Public Health 2019;16:771.

33 de Pablo P, Chapple ILC, Buckley CD, et al. Periodontitis in systemic rheumatic diseases. Nat Rev Rheumatol 2009;5:218-24.

34 Patel N, Milward M. The oral implications of mental health disorders Part 2: depression. Dent Update 2019;46:119-24.

35 Kisely S, Sawyer E, Siskind D, et al. The oral health of people with anxiety and depressive disorders - a systematic review and metaanalysis. J Affect Disord 2016;200:119-32.

36 Blak BT, Thompson M, Dattani H, et al. Generalisability of the health improvement network (thin) database: demographics, chronic disease prevalence and mortality rates. Inform Prim Care 2011;19:251-5.

37 Booth N. What are the read codes? Health Libr Rev 1994;11:177-82.

38 Maguire A, Blak BT, Thompson M. The importance of defining periods of complete mortality reporting for research using automated data from primary care. Pharmacoepidemiol Drug Saf 2009;18:76-83.

39 Horsfall L, Walters K, Petersen I. Identifying periods of acceptable computer usage in primary care research databases. Pharmacoepidemiol Drug Saf 2013;22:64-9.

40 Gokhale KM, Chandan JS, Toulis K, et al. Data extraction for epidemiological research (Dexter): a novel tool for automated clinical epidemiology studies. Eur J Epidemiol 2021;36:165-178.

41 Chandan JS, Keerthy D, Zemedikun DT, et al. The association between exposure to childhood maltreatment and the subsequent development of functional somatic and visceral pain syndromes. EClinicalMedicine 2020;23:100392.

42 Chandan JS, Thomas T, Bradbury-Jones C, et al. Intimate partner violence and temporomandibular joint disorder. J Dent 2019;82:98-100.

43 NHS Digital. Quality and Outcomes Framework (QOF) business rules v42 2019-2020 baseline release - NHS Digital, 2019. Available: https://digital.nhs.uk/data-and-information/data-collections-anddata-sets/data-collections/quality-and-outcomes-framework-qof/ quality-and-outcome-framework-qof-business-rules/quality-andoutcomes-framework-qof-business-rules-v42-2019-2020-baselinereleas [Accessed 31 Jul 2019].

44 Krishna MT, Subramanian A, Adderley NJ, et al. Allergic diseases and long-term risk of autoimmune disorders: longitudinal cohort study and cluster analysis. Eur Respir J 2019;54:1900476.

45 Chandan JS, Thomas T, Gokhale KM, et al. The burden of mental ill health associated with childhood maltreatment in the UK, using the health improvement network database: a population-based retrospective cohort study. Lancet Psychiatry 2019;6:926-34

46 Chandan JS, Thomas T, Bradbury-Jones C, et al. Female survivors of intimate partner violence and risk of depression, anxiety and serious mental illness. Br J Psychiatry 2020;217:562-7.

47 Chandan JS, Thomas T, Bradbury-Jones C, et al. Risk of cardiometabolic disease and all-cause mortality in female survivors of domestic abuse. J Am Heart Assoc 2020;9:e014580.

48 Chandan JS, Okoth K, Gokhale KM, et al. Increased cardiometabolic and mortality risk following childhood maltreatment in the United Kingdom. J Am Heart Assoc 2020;9:e015855.

49 Chandan JS, Thomas T, Lee S, et al. The association between idiopathic thrombocytopenic purpura and cardiovascular disease: a retrospective cohort study. J Thromb Haemost 2018;16:474-80.

50 Thomas T, Chandan JS, Subramanian A, et al. Epidemiology, morbidity and mortality in Behçet's disease: a cohort study using the health improvement network (thin). Rheumatology 2020;59:2785-95

51 Goel R, Chandan JS, Thayakaran R, et al. Cardiovascular and renal morbidity in Takayasu arteritis: a Population-Based retrospective cohort study from the United Kingdom. Arthritis Rheumatol 2021;73:504-11.

52 Chandan JS, Keerthy D, Gokhale KM, et al. The association between exposure to domestic abuse in women and the development of syndromes indicating central nervous system sensitization: a retrospective cohort study using UK primary care records. Eur J Pain 2021;25:ejp.1750.

53 Townsend P, Phillimore P, Beattie A. Health and deprivation: inequality and the North. 1988. London: Croom Helm Google Sch, 1988.

54 Lévesque LE, Hanley JA, Kezouh A, et al. Problem of immortal time bias in cohort studies: example using statins for preventing progression of diabetes. BMJ 2010;340:b5087.

55 Humphrey LL, Fu R, Buckley DI, et al. Periodontal disease and coronary heart disease incidence: a systematic review and metaanalysis. J Gen Intern Med 2008;23:2079-86.

56 Dietrich T, Sharma P, Walter C, et al. The epidemiological evidence behind the association between periodontitis and incident atherosclerotic cardiovascular disease. J Clin Periodontol 2013:40 Suppl 14:S70-84.

57 Haraszthy VI, Zambon JJ, Trevisan M, et al. Identification of periodontal pathogens in atheromatous plaques. J Periodontol 2000;71:1554-60.

58 Paraskevas S, Huizinga JD, Loos BG. A systematic review and meta-analyses on C-reactive protein in relation to periodontitis. $J$ Clin Periodontol 2008;35:277-90.

59 D'Aiuto F, Orlandi M, Gunsolley JC. Evidence that periodontal treatment improves biomarkers and CVD outcomes. J Clin Periodontol 2013;40 Suppl 14:S85-105.

60 Tonetti MS, D'Aiuto F, Nibali L, et al. Treatment of periodontitis and endothelial function. N Engl J Med 2007;356:911-20.

61 Graziani F, Gennai S, Solini A, et al. A systematic review and metaanalysis of epidemiologic observational evidence on the effect of periodontitis on diabetes an update of the EFP-AAP review. $J$ Clin Periodontol 2018;45:167-87.

62 Madianos PN, Koromantzos PA. An update of the evidence on the potential impact of periodontal therapy on diabetes outcomes. $J$ Clin Periodontol 2018:45:188-95.

63 Lalla E, Kunzel C, Burkett S, et al. Identification of unrecognized diabetes and pre-diabetes in a dental setting. $J$ Dent Res 2011:90:855-60.

64 Genco RJ, Schifferle RE, Dunford RG, et al. Screening for diabetes mellitus in dental practices: a field trial. J Am Dent Assoc 2014:145:57-64.

65 Commissioning standard for restorative dentistry NHS England and NHS improvement.

66 Borgnakke WS, Ylöstalo PV, Taylor GW, et al. Effect of periodontal disease on diabetes: systematic review of epidemiologic observational evidence. J Clin Periodontol 2013;40 Suppl 14:S135-52.

67 Araújo MM, Martins CC, Costa LCM, et al. Association between depression and periodontitis: a systematic review and meta-analysis. $J$ Clin Periodontol 2016;43:216-28.

68 Brennan DS, Spencer AJ, Roberts-Thomson KF. Quality of life and disability weights associated with periodontal disease. J Dent Res 2007;86:713-7.

69 de Pablo P, Dietrich T, McAlindon TE. Association of periodontal disease and tooth loss with rheumatoid arthritis in the US population. $J$ Rheumatol 2008;35:70-6.

70 Chen $\mathrm{H}-\mathrm{H}$, Huang N, Chen Y-M, et al. Association between a history of periodontitis and the risk of rheumatoid arthritis: a nationwide, population-based, case-control study. Ann Rheum Dis 2013;72:1206-11.

71 Lin T-C, Tseng C-F, Wang Y-H, et al. Patients with chronic periodontitis present increased risk for primary Sjögren syndrome: a nationwide population-based cohort study. PeerJ2018;6:e5109.

72 Borgnakke WS. Does treatment of periodontal disease influence systemic disease? Dent Clin North Am 2015;59:885-917.

73 McBrien KA, Souri S, Symonds NE, et al. Identification of validated case definitions for medical conditions used in primary care electronic medical record databases: a systematic review. J Am Med Inform Assoc 2018;25:1567-78.

74 Dietrich T, Ower P, Tank M, et al. Periodontal diagnosis in the context of the 2017 classification system of periodontal diseases and conditions - implementation in clinical practice. Br Dent $J$ 2019;226:16-22. 